were generally rated more favorably than M- test traits, and mild positive context effects may be observed for both judge groups and for both test traits. Differentiation of the judges does not appear to be a significant factor. These observations were supported by an analysis of variance in which the only significant effects were due to test traits $(F=219.5$, $\mathrm{df}=1 / 196, \mathrm{p}<.01)$ and context $(\mathrm{F}=8.8$, $\mathrm{df}=3 / 196, p<.01)$. The Judge Differentiation by Context interaction predicted by Berkowitz's discussion of differentiation and anchoring effects was lacking $(F=1.2, \mathrm{df}=3 / 196)$.

Results are consistent with an averaging-model analysis of context effects in that positive context effects were found, and these were essentially similar for both test stimuli, i.e., the Test by Context interaction was insignificant $(F=2.5$, df $=3 / 196)$. The perceptual assimilation-contrast model, on the other hand, received lack of support on two counts; first, judges who have demonstrated greater differentiation in social perception failed to show the predicted contrast effects, and second, test-trait/context pairings with the greatest distance (i.e., $\mathbf{M}-, \mathrm{H} ; \mathrm{M}+, \mathrm{L}$ ) did not result in contrast. The latter negative finding is consistent with the positive context effects reported by Anderson (1966) in test-context pairings of even greater disparity $(\mathrm{H}, \mathrm{L}$ and $\mathrm{L}, \mathrm{H})$, and raises doubts as to the existence of both assimilation and contrast effects in judgment of social stimuli.

The possibility exists that the presence of perceptual contrast is contingent on whether the anchor consists of contextual stimuli or initial attitude; Atkins \& Bieri (1968), for example, found consistent assimilation when contextual stimuli were considered, but, in intermittant responding, found an initial contrast with judges' initial attitude. It is significant, however, that this contrast dissipated with succeeding trials. Atkins (1966), in a design similar to that in which Berkowitz (1960) reported contrast effects, sequentially presented extreme statements prior to neutral ones, alternative pro and con anchors on each trial. As in the Atkins and Bieri study, initial contrast effects were replaced with the assimilation predicted by an averaging process as trials progressed. Only when anchors are univalent over trials in sequential presentation will contrast be noted, this contrast being due more to the rating scale imposed on $S$ than to perceptual changes. In the Bieri \& Atkins (1968) and Atkins (1966) studies, alternation of anchors over trials served to provide $S$ with a wider sample of rating categories than the unipolar presentation used by Berkowitz (1960). When S has the full-scale range in which to assign ratings, the artifact of contrasted ratings apparently is eliminated. In simultaneous presentation, width of rating samples is provided by practice and filler sets.

The presence of assimilation and contrast effects thus appears to be contingent on procedural conditions. The former requires the formation of a composite judgment (cf. Anderson \& Lampel, 1965), while the latter requires sequential presentation of stimuli, univalent anchors, and restricted response scales. Upshaw (1969) has suggested, on the basis of obtained category width and response dispersion in anchoring studies, that context effects reflect scaling phenomena rather than real changes in perception. He proposes that the contrast effects found by Sherif and his associates are due to the limited categorical response language provided by a narrow range of anchors and do not represent a shift in the affective value of test stimuli. Similarly, Anderson (1966) suggests that context effects reflect a shift in the rating of stimuli and not phenomenological meaning. Thus, both contrast and assimilation effects have been considered artifacts in the sense that neither represents a shift in perception but rather a shift in reference scale, the direction of which depends on the range of scale values effectively provided by the anchor.

While contrast effects due to contex tual anchors, when observed, may be at tributed to artifacts associated with stimulus presentation, the question remains whether such judge characteristics as differentiation can affect anchoring tendencies. The present findings, as well as the fact that consistent anchoring tendencies in Ss cannot be found across stimulus dimensions (Atkins, Meyers, \& Kujala, 1965), argue against this. Instead, it is proposed that perceptual contrast and assimilation, with its implication of differential effects of test-context distance, is inapplicable as an explanatory device in the study of context effects in impression formation.

\section{REFERENCES}

ANDERSON, N. H. Component ratings in impression formation. Psychonomic Science, $1966,6,279-280$.

ANDERSON, N. H. Likableness ratings of 555 personality-trait words. Journal of Personality \& Social Psychology, 1968, 9, 272-279.

ANDERSON, N. H., \& LAMPEL, A. Effect of context on ratings of personality traits. Psychonomic Science, 1965, 3, 433-434.

ATKINS, A. L. Own attitude and discriminability in relation to anchoring effects in judgment. Joumal of Personality \& Social Psychology, 1966, 4, 497-507.

ATKINS, A. L., \& BIERI, J. Effects of involvement level and contextual stimuli on social judgment. Joumal of Personality \& Social Psychology, 1968, 9, 197-204.

ATKINS, A. L., MEYERS, B. A., \& KUJALA, K. Anchoring tendencies as cognitive styles. Paper presented at meeting of the Eastern Psychological Association, Atlantic City, 1965. BERKOWITZ, L. The judgmental process in personality functioning. Psychological Review, $1960,67,130-142$.

BLANCHARD, W. A. Assimilation and contrast in interpersonal prediction with control for the interaction of real similarity and differential accuracy. Journal of Personality \& Social Psychology, 1966, 3, 567-573.

CHAPANIS, $A$. Color names for color space. American Scientist, 1965, 53, 327-346.

HOVLAND, C. I., HARVEY, O., \& SHERIF, M. Assimilation and contrast effects in reaction to communications and attitude change Joumal of Abnormal Social Psychology, 1957, 55, 244-252.

KAPLAN, M. F. Differentiation among targets in social perception as a function of response hierarchy. Psychonomic Science, 1968, 10, 227-228.

SHERIF, M., \& HOVLAND, C. J. Social judgment. New Haven: Yale University Press, 1961.

UPSHAW, H. S. The personal reference scale: An approach to social judgment. In L. Berkowitz (Ed.), Advances in experimental social psychology. Vol. 4. New York: Academic Press, 1969. Pp. 315-371.

NOTE

1. This research was largely supported by a faculty research grant awarded by the College Council, College of Liberal Arts \& Sciences, Northern Illinois University.

\title{
Paced vs. unpaced paired-associate recall ${ }^{1}$
}

JOHN P. HOUSTON, University
California, Los Angeles, Calif. 90024

In an attempt to eliminate a potentially confounding factor in the comparison of of paced and unpaced recall procedures, Ss first learned either an $A-B$ or successive $A-B, A-C$ paired-associate lists. One week later, Ss were asked to recall the first-list responses. Recall was either paced or unpaced. In 
contrast to the typical experiment, in which Ss in unpaced conditions are asked to recall both $B$ and $C$ responses, Ss in this experiment were informed that recall of the second-list responses was not necessary. Contrary to the prediction based upon the two-factor theory of forgetting, which states that more retroactive inhibition should be obtained with paced recall procedures, paced and unpaced conditions yielded equivalent amounts of retroactive inhibition. It was suggested that these data may be taken as further evidence for the suggestion that competition at the time of recall is not an important determinant of interference effects.

The two-factor theory of forgetting (Melton \& Irwin, 1940; Melton \& von Lackum, 1941) states that interference effects are determined by both unlearning and competition at the time of recall. Attempts to substantiate the competition notion have most often involved comparisons of paced and unpaced recall procedures (Keppel, 1968). According to the theory, conventional $2-\sec$ paced recall of a previously learned list should be heavily influenced by competition. On the other hand, unpaced recall procedures, typified by the modified modified free-recall test (MMFR), should be relatively free from competition effects. Thus, the general prediction has been that interference effects, both retroactive (RI) and proactive (PI), should be greater with paced than with unpaced recall procedures. Clear-cut support for this prediction has been difficult to obtain (Houston, 1968; Keppel, 1968). One reason for the lack of consistent differences between the two recall methods may lie in the fact that the two procedures differ in an important, and generally uncontrolled, manner. That is, in addition to differing in terms of the amount of time allowed for recall, the two procedures also differ in terms of the number of responses the $S$ is asked to recall. In the conventional paced test, the $S$ is generally asked to recall either the first- or second-list responses, while in the MMFR method, Ss are ty pically asked to recall both first- and second-list responses. Asking $S$ to recall both the critical set of responses and the interfering set of responses may reduce his ability to recall either set relative to Ss asked to recall only the critical set. Thus, a lack of a difference between paced and MMFR recall techniques may be due to offsetting factors. In the paced procedure, the $S$ is handicapped by the 2-sec time limit, but is not required to recall both sets of responses. MMFR Ss, on the other hand, have as much time as they wish to recall the responses, but must try to recall both sets of responses.
The present experiment attempted to eliminate this potentially confounding factor by comparing paced and unpaced recall procedures in which the Ss were never required to recall more than the critical set of first-list responses. The experiment involved a 2 by 2 design, with one factor referring to paced vs unpaced recall procedures and the other to the number of lists the $S$ learned, either successive A-B, A-C lists or a single A-B list. All Ss were tested for recall 1 week after list learning. In this $\mathrm{RI}$ design, Ss were instructed to recall only the A-B list responses, and not the second-list responses. Those who feel that competition is an important determinant of interference effects would predict that the paced procedure would yield a greater RI effect than the unpaced procedure.

\section{METHOD}

The four conditions were unsystematically arranged, such that each occurred once in each of 16 succeeding blocks of Ss. The 64 Ss, fulfilling a psychology course requirement, were assigned to this arrangement as they appeared in the laboratory. The two eight-item paired-associate lists were the $A-B, A-C$ lists developed by Barnes \& Underwood (1959). A detailed description of the lists is contained in their article. Within each condition, a given list was used as the first list for half the Ss, and as the second list for the remaining Ss. Four random presentation orders were developed to prevent serial learning of the responses, and each was used equally frequently as the starting order. All learning was conducted at a 2:2-sec presentation rate on a Stowe drum, with 4-sec intertrial and 45 -sec interlist intervals. All Ss learned the first, or A-B, list to a criterion of one perfect trial. Control Ss were then dismissed with instructions to return in 1 week. Experimental Ss learned the A-C list for 15 anticipation trials, and were then dismissed with the same instructions. Upon returning, Ss in the paced groups were shown each of the stimuli for $2 \mathrm{sec}$ in a new random order. Ss in the unpaced conditions were also shown the stimuli in a new random order, but were allowed as much time as they wished with each stimulus. The stimuli were presented with the memory drum. Responses were not exposed during the recall test. Control Ss recalled the responses from the single list they had learned. Experimental Ss were instructed to recall only the first-list responses, and were informed that recall of the second-list responses was not necessary

\section{RESULTS AND DISCUSSION}

The mean numbers of trials to first-list criterion required by the experimental paced, experimental unpaced, control paced, and control unpaced groups were
$11.50,12.31, \quad 11.00$, and 11.43, respectively. These means did not differ significantly ( $F s<1$ ), indicating that the four groups were equivalent in terms of learning ability. The mean numbers of correct second-list learning responses produced by the experimental paced and experimental unpaced groups were 92.19 and 86.13, respectively $(t<1)$.

The mean numbers of first-list responses recalled correctly by the experimental paced, experimental unpaced, control paced, and control unpaced, were 2.44, $2.88,4.81$, and 4.88 , respectively. The experimental-control main effect was significant $(F=20.36, d f=1 / 60, p<.01)$. Thus, the data display a strong retroactive inhibition effect. Somewhat surprising was the fact that the paced-unpaced main effect was not significant $(F<1)$. Unpaced procedures typically yield better overall recall than paced procedures, presumably because of the additional time allowed for recall. The reason for this disparate finding is not apparent.

More important, the interaction was not significant $(F<1)$. This is in contrast to the prediction based upon the two-factor theory, which states that more RI should be obtained with paced procedures. The absolute differences between experimental and control recall were, in fact, extremely similar in the paced (2.37) and unpaced conditions (2.00). These results may be taken as additional support for the suggestion that competition may be of little importance in the production of interference effects, and that other explanatory mechanisms must be sought to account for these effects. Houston (1968) has suggested that uncontrolled unlearning occurring in connection with undetected retention-interval rehearsal may be one such factor.

\section{REFERENCES}

BARNES, J. M., \& UNDERWOOD, B. J. "Fate" of first-list associations in transfer theory. Journal of Experimental Psychology, 1959, 58, 97-105.

HOUSTON, J. P. Competition in the two-factor theory of forgetting. Journal of Verbal Learning \& Verbal Behavior, 1968, 7, 496-500.

KEPPEL, G. Retroactive and proactive inhibition. In T. R. Dixon and D. L. Hoi ion (Eds.), Verbal behavior theory and its relation to general S-R theory. Englewood Cliffs, N.J.: Prentice-Hall, 1968. Pp. 172-213.

MELTON, A. W., \& IRWIN, J. M. The influence of degrees of interpolated learning on retroactive inhibitions and the overt transfer of specific responses. American Journal of Psychology, 53, 173-203.

MELTON, A. W., \& von LACKUM, W. J. Retroactive and proactive inhibition in retention: Evidence for a two-factor theory of retroactive inhibition. American Joumal of Psychology, 1941, 54, 157-173. NOTE

1. This work was supported by Public Health Service Grant MH 15336-02. 